\title{
A founder SDHB mutation in Portuguese paraganglioma patients
}

\section{Dear Editor}

We would like to report a genetic screening of $S D H B$, $S D H C, S D H D$ and SDHAF2 genes (hereafter abbreviated to $S D H x$ ) in patients with paragangliomas (PGL) and phaeochromocytomas (PCC) from northern Portugal.

PGL and PCC are neuroendocrine tumours that can be caused by heterozygous germline loss-of-function mutations in SDHx genes (Gimenez-Roqueplo et al. 2012). The spectrum of germline $S D H x$ mutations varies considerably among different countries, a circumstance that is related to the existence of several founder mutations. This is particularly marked in The Netherlands (Hensen et al. 2012), where six founder mutations were discovered, but evidence for founder effects was also observed for $S D H x$ mutations in Austrian (Janecke et al. 2010), Italian (Simi et al. 2005) and Spanish (Cascon et al. 2009) populations. In addition to familial PGL or PCC, germline $S D H x$ mutations have also been observed in patients without familial history of disease, sometimes classified as 'occult' familial cases (Lima et al. 2007). This phenomenon may be associated with the low penetrance of $S D H x$ mutations, which is about $50 \%$, although increasing in older individuals (Burnichon et al. 2009), and with the genomic imprinting observed in SDHD and SDHAF2 genes (Gimenez-Roqueplo et al. 2012).

We report the genetic study of 37 individuals diagnosed with PGL or PCC between 2009 and 2012, of which three were familial cases and 34 were sporadic. Sporadic cases were defined as those having no familial history of PGL or PCC in the parental and grandparental generations and disease was considered to be inherited when at least two first-degree relatives or two seconddegree relatives were affected by these tumours. Only the index cases from familial PGLs were considered for all the analyses. Patients displaying syndromic features associated with VHL, MEN2 or NF1 were excluded from the study. Written informed consent for genetic testing was obtained from all patients.

The majority of patients developed PGL (27/37; 73.0\%) and ten developed PCC (27.0\%). The clinical and pathological features of the 37 patients are shown in Table 1 .
We have identified seven different germline $S D H x$ mutations that were present in 20 of the 37 (54.1\%) patients. One mutation was located in SDHD and six were located in the $S D H B$ gene, while no alterations were found in $S D H C$ or SDHAF2 genes.

We identified three cases of familial PGL. In the first, the index case (multiple HN PGLs and a thoracic PGL) was found to harbour a germline SDHD frameshift mutation (L139FfsX29) that was shared by the two relatives with disease (one with multiple abdominal PGLs and another with multiple head and neck PGLs). Two additional families with PGL were identified: in one, the index case developed a malignant abdominal PGL (with bone metastases) and her uncle had also developed a malignant abdominal PGL with brain metastases; in a third family, the index case presented abdominal PGL and his mother had developed multiple head and neck PGLs. All the affected relatives of these two families harboured a large germline $15678 \mathrm{bp}$ deletion in the $S D H B$ gene, which encompasses the promoter and exon 1.

In the 34 patients in whom no familial relationships could be established (considered as sporadic cases), we have identified six germline $S D H x$ mutations, all in $S D H B$, that were present in 17 patients (50.0\% of sporadic cases). The majority of the germline-mutated patients harboured the $S D H B 15678$ bp deletion (9/17, 52.9\%), four patients presented SDHB frameshift mutations (P56delYfsX5 and S198AfsX22 in three patients) that lead to premature stop codons and four patients presented germline missense mutations (A43P, R11H and R230H in two patients). All the aforementioned $S D H B$ mutations were previously described as pathogenic (Bayley et al. 2005). In patients without SDHx mutations, we have screened for $V H L$, TMEM127 and MAX mutations, but none were disclosed.

The finding that a large number of patients in this series $(11 / 37 ; 29.7 \%)$ presented the germline $S D H B$ 15678 bp deletion prompted us to study the haplotypic variability in the flanking regions upstream (using the SNPs: rs1569754, rs3946080, rs2143811 and rs5772743) and downstream (using the SNPs: rs7545518, rs7545499

Published by Bioscientifica Ltd. 
Table 1 Clinical characteristics of PGL and PCC patients with or without SDHx mutations

\begin{tabular}{|c|c|c|c|c|}
\hline & $\begin{array}{c}\text { All patients } \\
(n=37)\end{array}$ & $\begin{array}{l}\text { Patients with germline } \\
\text { mutations } \mathbf{s}^{\mathrm{a}}(n=20)\end{array}$ & $\begin{array}{l}\text { Patients without } \\
\text { germline mutations } \\
(n=17)\end{array}$ & $\begin{array}{c}\text { Mutated vs } \\
\text { non-mutated } \\
\text { cases } P \text { value }^{\text {b }}\end{array}$ \\
\hline Mean age at diagnosis (years) & $40.0 \pm 16.0$ & $33.8 \pm 14.6$ & $47.4 \pm 14.8$ & 0.008 \\
\hline \multicolumn{5}{|l|}{ Gender } \\
\hline Male & $21(56.8)$ & $14(70.0)$ & $7(41.2)$ & 0.078 \\
\hline Female & $16(43.2)$ & $6(30.0)$ & $10(58.8)$ & \\
\hline Multiple tumours & $1(2.7)$ & $1(5.0)$ & 0 & NS \\
\hline Mean tumour size $(\mathrm{cm})$ & $7.2 \pm 3.6$ & $7.1 \pm 3.2$ & $7.3 \pm 4.1$ & NS \\
\hline \multicolumn{5}{|l|}{ Localization ${ }^{c}$} \\
\hline Adrenal glands & $10(27.0)$ & $2(10.0)$ & $8(47.1)$ & 0.023 \\
\hline \multicolumn{5}{|l|}{ Extra-adrenal } \\
\hline Head and neck & 7 (18.9) & $4(20.0)$ & $3(17.6)$ & \\
\hline Thorax & $4(10.8)$ & $4(20.0)$ & 0 & \\
\hline \multirow{2}{*}{\multicolumn{5}{|c|}{ Hormonal hypersecretion $^{d}$}} \\
\hline & & & & \\
\hline Norepinephrine & $21(67.7)$ & $12(75.0)$ & $9(60.0)$ & NS \\
\hline Epinephrine & $5(17.2)$ & $0(0)$ & $5(38.5)$ & 0.011 \\
\hline Dopamine & $14(46.7)$ & $7(43.8)$ & $7(50.0)$ & NS \\
\hline Metanephrine & $6(20.0)$ & 0 & $6(35.3)$ & 0.005 \\
\hline Normetanephrine & $21(67.7)$ & $11(68.8)$ & $10(66.7)$ & NS \\
\hline None & $7(23.3)$ & $3(18.8)$ & $4(28.6)$ & NS \\
\hline $\begin{array}{l}\text { Locally invasive disease without } \\
\text { metastases }\end{array}$ & $6(16.2)$ & $3(15.0)$ & $3(17.6)$ & NS \\
\hline Distant metastases & $11(29.7)$ & $7(35.0)$ & $4(23.5)$ & NS \\
\hline Mortality & $4(10.8)$ & $3(15.0)$ & $1(5.9)$ & NS \\
\hline
\end{tabular}

and rs7536679) of the deletion breakpoint, in order to assess whether this deletion occurred in multiple independent events or whether it was a single event that settled in the population. After selective amplification of the deleted allele in the 11 deletion-positive patients, we observed that, in all cases, the deletion was associated with the same haplotype (haplotype 3 - Table 2); selective amplification of the WT alleles (in the same 11 deletionpositive patients) disclosed two different haplotypes. Furthermore, haplotype reconstruction (using the same

Table 2 Haplotypes detected in PGL patients, control population and other European populations

\begin{tabular}{|c|c|c|c|c|c|c|c|c|c|c|c|c|}
\hline \multirow[b]{2}{*}{ Haplotype } & \multicolumn{7}{|c|}{ SNPs } & \multicolumn{5}{|c|}{ Chromosome frequency (\%) } \\
\hline & rs1569754 & rs3946080 & rs2143811 & rs5772743 & rs7545518 & rs7545499 & rs7536679 & $\begin{array}{c}\mathrm{PGL}^{\mathrm{a}} \\
n=11\end{array}$ & $\begin{array}{c}\text { NPO } \\
n=80\end{array}$ & $\begin{array}{c}\text { GBR } \\
n=178\end{array}$ & $\begin{array}{c}\text { FIN } \\
n=186\end{array}$ & $\begin{array}{c}\text { TSI } \\
n=196\end{array}$ \\
\hline Hap1 & $C$ & A & $\mathrm{C}$ & $A$ & $A$ & $A$ & $\mathrm{~T}$ & 0 & 5.0 & 0 & 0 & 0 \\
\hline Hap2 & $C$ & A & C & $A$ & $\mathrm{G}$ & G & C & 0 & 22.5 & 28.7 & 29.6 & 29.6 \\
\hline Hap3 & $C$ & A & $C$ & $-{ }^{b}$ & A & A & $\mathbf{T}$ & 100 & 45.0 & 52.3 & 54.8 & 47.5 \\
\hline Hap4 & $C$ & $A$ & $\mathrm{C}$ & $-b$ & $\mathrm{G}$ & G & C & 0 & 13.8 & 7.3 & 8.6 & 8.2 \\
\hline Hap5 & $\mathrm{T}$ & G & $\mathrm{T}$ & $A$ & $A$ & A & $\mathrm{T}$ & 0 & 1.3 & 0 & 0 & 0 \\
\hline Hap6 & $\mathrm{T}$ & G & $\mathrm{T}$ & A & $\mathrm{G}$ & G & C & 0 & 12.5 & 11.8 & 7.0 & 14.8 \\
\hline
\end{tabular}

NPO, North of Portugal (control population); GBR, British in England and Scotland (1000 Genomes Project population); FIN, Finnish in Finland (1000 Genomes Project population); TSI, Toscani in Italia (1000 Genomes Project population); Hap3, given in bold, indicates the haplotype found in all deleted alleles.

aPGL, includes only the deleted alleles from the 11 patients harbouring the SDHB 15678 bp deletion.

bash indicates adenine deletion.

http://erc.endocrinology-journals.org
$\begin{aligned} & 2013 \text { Society for Endocrinology } \\ & \text { DOI: } 10.1530 / \text { ERC-12-0399 }\end{aligned}$
Published by Bioscientifica Ltd. 
SNPs) in 40 healthy individuals from northern Portugal (in whom we confirmed the absence of the deletion) identified four additional haplotypes (Table 2). Four of these haplotypes were detected in other European populations (Great Britain, Finland and Italy) in comparable frequencies (Table 2). The frequency of haplotype 3 in the deleted chromosomes is significantly different from its frequency in the control population $(P=0.0005)$.

SDHA and SDHB immunohistochemistry in the tumour tissue showed that all patients with $S D H x$ mutations had loss of SDHB and presence of SDHA expression in the tumour. On the other hand, patients without SDHx mutations presented both SDHB and SDHA expression, discarding the existence of additional $S D H x$ alterations, such as large deletions, that would be missed by Sanger sequencing.

When performing genotype-phenotype correlations, we observed that patients with $S D H x$ mutations had a lower mean age at diagnosis $(P=0.008)$, developed tumours that were more frequently located in extraadrenal sites $(P=0.023)$ and were predominantly men $(P=0.078)$ (Table 1$)$. The tumours that occurred in patients with $S D H x$ mutations presented a signature of low secretion of epinephrine $(P=0.011)$ and metanephrine $(P=0.005)$ (Table 1$)$ when compared with tumours without $S D H x$ mutations. Malignant and lethal tumours were more frequently observed in patients with $S D H x$ mutations (35.0 and $15.0 \%$ respectively) than in nonmutated cases (23.5 and 5.9\% respectively), although the difference was not statistically significant.

In the series of PGL/PCC presented here, half of the patients without familial history of disease $(17 / 34 ; 50.0 \%)$ harboured germline $S D H x$ mutations; altogether, germline SDHx mutations were the primary cause of PGL and PCC in $54.1 \%(20 / 37)$ patients.

The prevalence of $S D H x$ mutations in this cohort is high and comparable to the one found in a large series of French PGL patients (Burnichon et al. 2009). The high frequency of $S D H x$ mutations in our series is likely attributable to the prevalence of the SDHB $15678 \mathrm{bp}$ deletion $(55.0 \%$ of the $S D H x$-mutated patients). To the best of our knowledge, this is only the second report of the SDHB 15678 bp deletion in PGL/PCC patients, despite the large number of studies in this topic, raising the hypothesis that the high frequency of this deletion in Portuguese patients can be related to a founder effect. A founder effect for this specific deletion had already been proposed by Cascon et al. (2008), who studied five families, all of them harbouring this deletion and showing a conserved breakpoint. Notably, of the five families, one was from Porto, Portugal, a second was a Brazilian family and the remaining three were of Spanish origin, more specifically from Galicia (Cascon et al. 2008).

Our results show that the deletion breakpoint is conserved among 11 patients with PGL/PCC and also matches the previously reported breakpoint (Cascon et al. 2008). None of these 11 patients have familial relationships, but all come from northern Portugal. Furthermore, we have shown that all deleted alleles share a common haplotype (haplotype 3), in a significantly higher frequency than in control, healthy individuals (45.0\%). The lack of variation in the up- and downstream flanking regions of the deleted allele (in contrast to the normal alleles from the control population, where six different haplotypes were found) fits with a founder effect for this deletion, which has probably settled in the northern Portuguese/Galician populations. A recent study of $S D H x$ mutations in Portuguese PGL/PCC patients from central and southern Portugal did not find this deletion (Domingues et al. 2012), further suggesting that the founder effect is related to northern Portuguese/Galician populations.

Our results support the previously reported association between $S D H x$ mutations and lower age at diagnosis and extra-adrenal location (Burnichon et al. 2009). The association between absence of $S D H x$ mutations and higher levels of epinephrine and metanephrine hypersecretion may reflect the higher proportion of PCC in this subgroup of patients, as epinephrine is synthesized and stored only in the adrenal medulla (and metanephrine is its main metabolite) whereas norepinephrine and dopamine are also synthesized in the peripheral sympathetic nerves.

Summing up, we present data showing that the majority of PGL in northern Portugal patients develop as a consequence of germline $S D H x$ mutations, in particular a founder mutation in the $S D H B$ gene (15 678 bp deletion). Our results support the suggestion by Hensen et al. (2012) that population specificities, regarding the presence of founder germline $S D H x$ mutations, should be taken into account whenever deciding about the genetic testing in PGL/PCC patients.

Raquel G Martins $s^{2,3 *}$
Joana B Nunes ${ }^{1,2 *}$
Valdemar Máximo $^{1,2}$
Paula Soares
Joana Peixoto $^{1}$
Telmo Catarino $^{1}$

Published by Bioscientifica Ltd. 


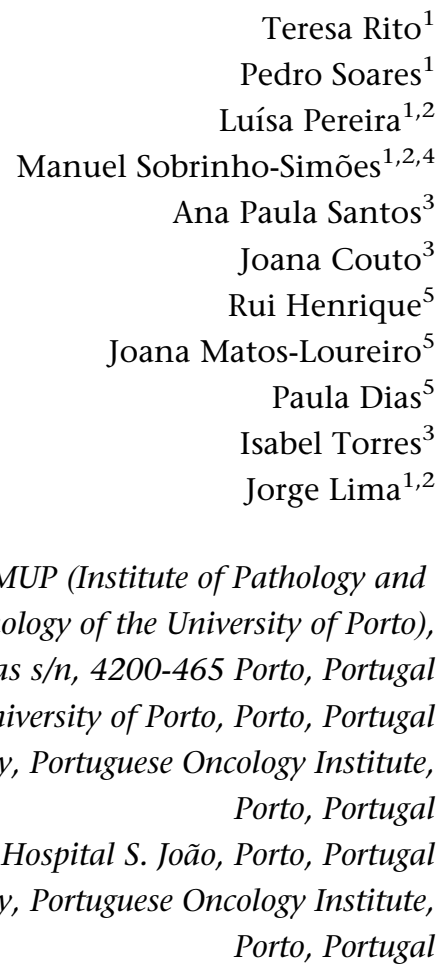

(Correspondence should be addressed to J Lima); email: jlima@ipatimup.pt

$\left({ }^{*} \mathrm{R}\right.$ G Martins and J B Nunes should be considered as joint first authors)

\section{Declaration of interest}

The authors declare that there is no conflict of interest that could be perceived as prejudicing the impartiality of the research reported.

\section{Funding}

This work was supported by Fundação para a Ciência e Tecnologia (Program Ciência 2007 to V Máximo, Program Ciência 2008 to J Lima, grant numbers SFRH/BPD/64233/2009 to Pedro Soares, PIC/IC/83037/2007 to V Máximo, and PTDC/CS-ANT/113832/2009 to T Rito). Further funding by Portuguese Foundation for Science and Technology by the project 'Microenvironment, metabolism and cancer' partially supported by Programa Operacional Regional do Norte (ON.2-O Novo Norte) under the Quadro de Referencia Estrategico Nacional (QREN) and through the Fundo Europeu de Desenvolvimento Regional (FEDER). IPATIMUP is an Associate Laboratory of the Portuguese Ministry of Science, Technology and Higher Education that is partially supported by the FCT.

\section{Acknowledgements}

The authors thank Ana Dias for the excellent support in sequencing experiments.

\section{References}

Bayley JP, Devilee P \& Taschner PE 2005 The SDH mutation database: an online resource for succinate dehydrogenase sequence variants involved in pheochromocytoma, paraganglioma and mitochondrial complex II deficiency. BMC Medical Genetics 6 39. (doi:10.1186/14712350-6-39)

Burnichon N, Rohmer V, Amar L, Herman P, Leboulleux S, Darrouzet V, Niccoli P, Gaillard D, Chabrier G, Chabolle F et al. 2009 The succinate dehydrogenase genetic testing in a large prospective series of patients with paragangliomas. Journal of Clinical Endocrinology and Metabolism 94 2817-2827. (doi:10.1210/jc.2008-2504)

Cascon A, Landa I, Lopez-Jimenez E, Diez-Hernandez A, Buchta M, Montero-Conde C, Leskela S, Leandro-Garcia LJ, Leton R, RodriguezAntona C et al. 2008 Molecular characterisation of a common SDHB deletion in paraganglioma patients. Journal of Medical Genetics $\mathbf{4 5}$ 233-238. (doi:10.1136/jmg.2007.054965)

Cascon A, Pita G, Burnichon N, Landa I, Lopez-Jimenez E, Montero-Conde C, Leskela S, Leandro-Garcia LJ, Leton R, Rodriguez-Antona C et al. 2009 Genetics of pheochromocytoma and paraganglioma in Spanish patients. Journal of Clinical Endocrinology and Metabolism 94 1701-1705. (doi:10. 1210/jc.2008-2756)

Domingues R, Montalvao P, Magalhaes M, Santos R, Duarte L \& Bugalho MJ 2012 Identification of three new variants of sdhx genes in a cohort of Portuguese patients with extra-adrenal paragangliomas. Journal of Endocrinological Investigation 35 975-980.

Gimenez-Roqueplo AP, Dahia PL \& Robledo M 2012 An update on the genetics of paraganglioma, pheochromocytoma, and associated hereditary syndromes. Hormone and Metabolic Research 44 328-333. (doi:10.1055/s-0031-1301302)

Hensen EF, van Duinen N, Jansen JC, Corssmit EP, Tops CM, Romijn JA, Vriends AH, van der Mey AG, Cornelisse CJ, Devilee P et al. 2012 High prevalence of founder mutations of the succinate dehydrogenase genes in The Netherlands. Clinical Genetics 81 284-288. (doi:10.1111/j.13990004.2011.01653.x)

Janecke AR, Willett-Brozick JE, Karas C, Hasipek M, Loeffler-Ragg J \& Baysal BE 2010 Identification of a 4.9-kilo base-pair Alu-mediated founder SDHD deletion in two extended paraganglioma families from Austria. Journal of Human Genetics 55 182-185. (doi:10.1038/jhg.2009.142)

Lima J, Feijao T, Ferreira da Silva A, Pereira-Castro I, Fernandez-Ballester G, Maximo V, Herrero A, Serrano L, Sobrinho-Simoes M \& Garcia-Rostan G 2007 High frequency of germline succinate dehydrogenase mutations in sporadic cervical paragangliomas in northern Spain: mitochondrial succinate dehydrogenase structure-function relationships and clinical-pathological correlations. Journal of Clinical Endocrinology and Metabolism 92 4853-4864. (doi:10.1210/jc.2007-0640)

Simi L, Sestini R, Ferruzzi P, Gagliano MS, Gensini F, Mascalchi M, Guerrini L, Pratesi C, Pinzani P, Nesi G et al. 2005 Phenotype variability of neural crest derived tumours in six Italian families segregating the same founder SDHD mutation Q109X. Journal of Medical Genetics 42 e52. (doi:10.1136/jmg.2004.030353)

Received in final form 1 October 2013

Accepted 3 October 2013

Made available online as an Accepted Preprint

3 October 2013 http://erc.endocrinology-journals.org DOI: 10.1530/ERC-12-0399
(C) 2013 Society for Endocrinology Printed in Great Britain
Published by Bioscientifica Ltd. 